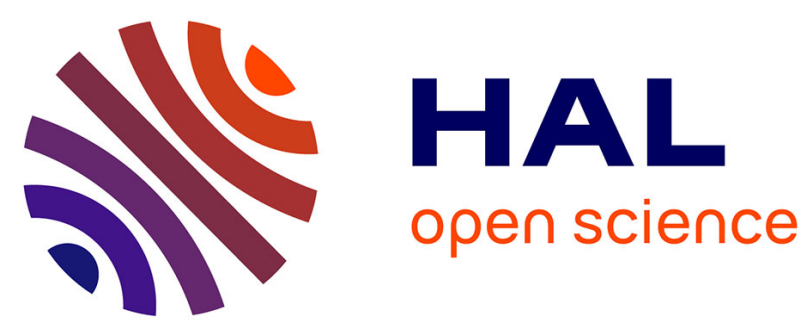

\title{
Obesity impairs general health-related quality of life (HR-QoL) in premenopausal women to a greater extent than the polycystic ovary syndrome (PCOS)
}

Francisco Alvarez-Blasco, Manuel Luque-Ramírez, Hector F Escobar-Morreale

\section{- To cite this version:}

Francisco Alvarez-Blasco, Manuel Luque-Ramírez, Hector F Escobar-Morreale. Obesity impairs general health-related quality of life (HR-QoL) in premenopausal women to a greater extent than the polycystic ovary syndrome (PCOS). Clinical Endocrinology, 2010, 73 (5), pp.595. 10.1111/j.13652265.2010.03842.x . hal-00552615

\section{HAL Id: hal-00552615 https://hal.science/hal-00552615}

Submitted on 6 Jan 2011

HAL is a multi-disciplinary open access archive for the deposit and dissemination of scientific research documents, whether they are published or not. The documents may come from teaching and research institutions in France or abroad, or from public or private research centers.
L'archive ouverte pluridisciplinaire HAL, est destinée au dépôt et à la diffusion de documents scientifiques de niveau recherche, publiés ou non, émanant des établissements d'enseignement et de recherche français ou étrangers, des laboratoires publics ou privés. 


\section{CLINICAL ENDOCRINOLOGY}

\section{Obesity impairs general health-related quality of life (HR- QoL) in premenopausal women to a greater extent than the polycystic ovary syndrome (PCOS)}

\begin{tabular}{|c|c|}
\hline Journal: & Clinical Endocrinology \\
\hline Manuscript ID: & CEN-2010-000337.R1 \\
\hline Manuscript Type/Office: & 2 Original Article - Europe, excluding UK \\
\hline $\begin{array}{l}\text { Date Submitted by the } \\
\text { Author: }\end{array}$ & 08-Jun-2010 \\
\hline Complete List of Authors: & $\begin{array}{l}\text { Alvarez-Blasco, Francisco; Hospital Ramón y Cajal, Department of } \\
\text { Endocrinology } \\
\text { Luque-Ramírez, Manuel; Hospital Ramón y Cajal, Department of } \\
\text { Endocrinology; La Princesa University Hospital, Department of } \\
\text { Endocrinology } \\
\text { Escobar-Morreale, Hector; Hospital Ramón y Cajal, Department of } \\
\text { Endocrinology }\end{array}$ \\
\hline Key Words: & $\begin{array}{l}\text { Hirsutism < Conditions: < Ovary, Female infertility < Conditions: < } \\
\text { Ovary, Polycystic ovary syndrome < Conditions: < Ovary }\end{array}$ \\
\hline
\end{tabular}

\section{S) ScholaroNE


1 Title: Obesity impairs general health-related quality of life (HR-QoL) in premenopausal women to a 2 greater extent than the polycystic ovary syndrome (PCOS).

3

4 Short Title: Obesity, PCOS and HR-QoL

5

6 Escobar-Morreale, M.D., Ph.D.

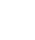
CIBERDEM, Spain. hescobarm.hrc@salud.madrid.org de Investigación Carlos III.

Authors: Francisco Álvarez-Blasco, M.D. Ph.D., Manuel Luque-Ramírez, M.D. Ph.D. and Héctor F.

Affiliation: Department of Endocrinology, Hospital Universitario Ramón y Cajal, Universidad de Alcalá, and Instituto Ramón y Cajal de Investigación Sanitaria IRYCIS, E-28034, Madrid, and Centro de Investigaciones Biomédicas en Red de Diabetes y Enfermedades Metabólicas Asociadas

Correspondence: Héctor F. Escobar-Morreale, M.D., Ph.D., Department of Endocrinology, Hospital Universitario Ramón y Cajal, Carretera de Colmenar km 9'1, E-28034 Madrid, Spain. E-mail:

Key words: Quality of life, obesity, polycystic ovary syndrome.

Acknowledgements: This study was supported by the Spanish Ministry of Science and Innovation, Instituto de Investigación Carlos III, grant FIS PI080944. CIBERDEM is also an initiative of Instituto

Financial disclosure: The Authors have nothing to disclose

6 Word count: 2667; Word Count for Abstract: 221; Number of Tables: 4; Number of Figures: 1 
Obesity, PCOS and HR-QoL - 2 -

\section{STRUCTURED SUMMARY}

Objective: Obesity is frequently associated with the polycystic ovary syndrome (PCOS), and both 30 conditions may impact the health-related quality of life (HR-QoL) of affected patients. We aimed to 31 estimate the relative impact of obesity and PCOS on the general HR-QoL of premenopausal women. 32 Design: Case-control study.

33 Patients: Consecutive overweight and obese premenopausal women seeking advice for weight loss, of 34 whom 32 were diagnosed with PCOS and 72 had no evidence of androgen excess and were considered 35 controls.

36 Measurements: Spanish versions of the Short Form 36 Health Survey (SF-36) questionnaire and the 37 Nottingham Health Profile (NHP) were self-administered by the women.

38 Results: PCOS patients and controls had similar body mass index, yet controls were older. General 39 HR-QoL mean scores were similar in both groups, yet PCOS patients scored worse in the role40 emotional item of SF-36, and controls scored worse in the pain item of NHP. Increasing grades of 41 obesity, on the contrary, were associated with worse scores in the NHP and SF-36 items related to 42 general and physical aspects of HR-QoL. When compared with the standards established for the 43 Spanish general population, both PCOS patients and controls frequently presented with abnormal 44 scores, yet only increasing grades of obesity were associated with more frequent abnormal scoring.

45 Conclusions: Obesity impaired general HR-QoL to a greater extent than PCOS in overweight and 46 obese premenopausal women. 


\section{Introduction}

Health-related quality of life (HR-QoL) is a multidimensional concept that comprises physical, emotional and social concepts associated with a specific disease and its management. ${ }^{1}$ The polycystic ovary syndrome (PCOS) is a life-time disorder that appears in up to $6.5 \%$ of Spanish premenopausal women. ${ }^{2}$ The clinical signs and symptoms of PCOS, derived from the androgen excess and ovulatory dysfunction that define the syndrome ${ }^{3,4}$ include hirsutism, acne, menstrual irregularity and infertility and have a peripubertal onset. Therefore, these signs and symptoms exert a negative impact on mood and psychological function of affected women for decades. Not surprisingly, depression is frequent in PCOS patients and the presence of hirsutism has been described in association with anxiety and psychological complaints. ${ }^{5-10}$

Moreover, PCOS is frequently associated with insulin resistance, obesity and related metabolic disorders. ${ }^{11}$ Obesity in particular is present in almost $50 \%$ of PCOS patients in clinical series ${ }^{11}$ and may impair by itself the HR-QoL of women. ${ }^{12-15}$ However, to date it is unclear whether PCOS by itself, $^{16}$ or its associations with obesity and other metabolic derangements, ${ }^{17-19}$ are the major contributors to the impaired HR-QoL previously reported women in whom both conditions, PCOS and weight excess, coexist.

64 We aimed to delineate the specific contributions of PCOS and of weight excess to the impairment in the general HR-QoL of premenopausal women seeking advice for weight loss.

\section{Material and Methods}

Patients

The present study derived from an earlier report addressing the prevalence of PCOS among 71 otherwise healthy premenopausal women seeking medical advice for weight loss. ${ }^{20}$ In brief, all the 72 premenopausal women referred by their general physicians to the Department of Endocrinology of 73 Hospital Universitario Ramón y Cajal, for weight loss from May 1, 2002, through December 31, 2005 , 74 were prospectively evaluated. All the women were referred from the primary care facilities attending a 
Obesity, PCOS and HR-QoL - 4 -

75 specific suburb of Madrid which has a medium-low socio-economic status. Inclusion criteria required 76 being referred exclusively for weight loss as the main complaint, having a body mass index (BMI, 77 calculated as weight in kilograms divided by the square of height in meters) above 25, being younger 78 than 50 years, and not having classic menopausal symptoms such as hot flushes. Women taking 79 medications that might interfere with hormone profiles, such as contraceptives or insulin sensitizers, 80 were also excluded.

81 The diagnosis of PCOS used the criteria derived from the 1990 conference sponsored by the 82 National Institute of Child and Human Development: clinical and/or biochemical hyperandrogenism 83 together with ovulatory dysfunction, after excluding secondary aetiologies such as non-classic adrenal 84 hyperplasia, hyperprolactinaemia and androgen-secreting tumours. ${ }^{21}$ Having both hyperandrogenism and ovulatory dysfunction, and although an ovarian ultrasound scan was not obtained, the PCOS 86 patients diagnosed here also fulfilled more recent definitions of PCOS., ${ }^{3,422}$ The assays and specific 87 methods used to establish these criteria have been described in detail elsewhere. ${ }^{20,23,24}$ The study was approved by the local ethics committee and all participants gave written informed consent.

From a total of 113 consecutive women recruited, 32 had PCOS, 3 had hyperandrogenemia 90 without evidence of oligoovulation, 2 had idiopathic hirsutism, 2 had isolated chronic oligomenorrhea 91 without clinical or biochemical hyperandrogenism, and 2 had oligomenorrhea and hyperprolactinemia, 92 precluding the diagnosis of PCOS. The remaining 72 women had no evidence of hyperandrogenism or 93 reproductive abnormalities and were considered as the nonhyperandrogenic control group for further 94 comparisons. ${ }^{20}$ Because none of the control women had clinical or biochemical hyperandrogenism or 95 menstrual disturbances or ovulatory dysfunction, the presence of PCOS according to recent 96 definitions $s^{3,4,22}$ was ruled out reliably in all of them even in the absence of an ovarian ultrasound scan. 97 The present study focuses on the comparison of general HR-QoL among the 32 PCOS patients with 98 the 72 controls. 
We measured general HR-QoL using the Spanish versions of the Short Form 36 Health Survey (SF-36) questionnaire ${ }^{25}$ and the Nottingham Health Profile (NHP). ${ }^{26}$

The SF-36 questionnaire uses 36 questions to estimate HR-QoL in eight scaled scores, which are 105 the weighted sums of the questions in their section. Four scores measure physical health (physical 106 functioning, role-physical, bodily pain and general health) and four measure mental health (vitality, 107 social functioning, role-emotional and mental health). ${ }^{27}$ Each scale is directly transformed into a 0-100 108 scale on the assumption that each question carries equal weight. The higher the score, the better the 109 result for the particular item.

110 The NHP is an auto-administered test of 45 questions distributed into two parts. Part I includes 38 111 questions grouped into six sections: physical ability (8 questions), pain (8 questions), sleep (5 112 questions), social isolation (5 questions), emotional reactions (9 questions), and energy level (3 113 questions). Part II consists of 7 general questions that may not be applicable and is seldom used 114 nowadays. Each question has to be answered as 'yes' or 'no'. Each scale is weighted, and the weights 115 are transformed to yield scores from 0 (no distress) to 100 (maximum distress). Scores are obtained for 116 each section and combined in order to obtain a total score.

117 The SF-36 and NHP questionnaires were self-adminstered by the women early in the morning and 1183 to 8 days after a spontaneous or progesterone-induced withdrawal menstrual bleeding. We compared 119 the results of the PCOS patients with those of the controls, and we also compared the results of both 120 groups with the reference percentiles established for the Spanish general population of the same age121 range and sex..$^{28,29}$ Values above the $95^{\text {th }}$ percentile were considered abnormal for the NHP, and values 122 below the $5^{\text {th }}$ percentile were considered abnormal for the SF-36.

124 Statistical analysis

We express results as means \pm SD unless stated otherwise. We used the Kolmogorov-Smirnov test 127 to estimate the distribution of continuous variables, and we applied logarithmic or square root 128 transformations as needed to ensure normality. We submitted normally distributed variables to a 129 general linear model that included having PCOS or being a control as the independent variable, and 
Obesity, PCOS and HR-QoL - 6 -

130 included age as a covariate to correct for the difference in age among PCOS patients and controls.

131 Variables that remained skewed even after mathematical transformation were submitted to Mann-

132 Whitney $\mathrm{U}$ tests and, for variables showing statistically significant differences, the possible impact of

133 the difference in age between patients and controls was explored by analyzing Spearman's correlation

134 of these variables with age in the whole population.

135 The impact of the grade of obesity on HR-QoL indexes was explored considering PCOS patients

136 and controls as a whole. We used the Kruskall-Wallis non-parametric ANOVA and, when this test

137 resulted in statistically significant differences, we identified which grades of obesity caused these

138 differences by using repeated Mann-Whitney U tests in which the Bonferroni correction was applied

139 to the level of significance. For nominal and ordinal variables we applied Pearson's $\chi^{2}$ or Fisher's

140 exact tests, as appropriate.

141 We used the PASW Statistics 18 software (SPSS Inc. Chicago, Illinois) to compute statistic

142 analyses. A $\alpha=0.05$ level of significance was used for all analyses except when Bonferroni

143 adjustments were needed in order to correct for multiple comparisons among subgroups of women.

145 Results

146

147 Clinical characteristics of overweight and obese premenopausal women depending on the presence or 148 absence of PCOS

149 The comparisons of the clinical and biochemical characteristics of PCOS patients and controls

150 are included in Table 1. We introduced age was as a covariate in the general linear model because

151 PCOS patients were younger compared with controls. PCOS patients presented with increased

152 hirsutism scores, androgen, triglycerides and luteinizing hormone concentrations, and reduced sex

153 hormone-binding globulin and estradiol levels. PCOS patients were insulin resistant compared with

154 the controls, and therefore had increased fasting insulin levels and homeostasis model assessment

155 insulin resistance and $\beta$-cell function indexes, and reduced insulin sensitivity index as calculated from

156 the results of an oral glucose tolerance test. ${ }^{30}$ The number of pregnancies and deliveries was reduced in

157 PCOS patients when compared with the controls. 


\section{Impact of PCOS on the HR-QoL of overweight and obese premenopausal women}

160 The only statistically significant difference among PCOS women and controls in the NHP 161 consisted of a reduced score in the bodily pain item of PCOS patients compared with the controls, 162 whereas no difference was observed in any other item (Figure 1). Because this variable was skewed 163 even after mathematical transformations we used nonparametric correlation to estimate a possible

164 influence of the older age of the controls in their higher bodily pain scores. These scores showed a 165 statistically significant yet very weak correlation with age $\left(\mathrm{r}^{2}=0.065, P=0.009\right)$.

166 Similarly, PCOS was associated only with a worse score in the role-emotional item of the SF-36 167 test even after correcting for the difference in age, whereas no difference was observed in any other 168 item (Figure 1).

169 When compared with the reference values established for the Spanish population, the percentages 170 of subjects with abnormal scores in the NHP were not different in PCOS patients and controls, yet 171 both groups showed a large percentage of women showing abnormally increased scores in the energy

172 and mobility items and in the total score (Table 2). The percentage of women with scores abnormally 173 reduced with respect to the reference populational data was higher in PCOS patients compared with 174 the controls in the role-emotional item of SF-36, and there was a large percentage of women in both 175 groups presenting with abnormal scores in the general health, physical functioning, role-emotional and 176 social functioning items of the SF-36 test (Table 2).

177

178 Impact of the grade of obesity on the HR-QoL of overweight and obese premenopausal women

179 For these analyses we considered PCOS patients and controls as a whole, and we classified them 180 according to their BMI into overweight (BMI $25.0-29.9 \mathrm{~kg} / \mathrm{m}^{2}$ ), grade 1 obesity (BMI $30.0-34.9$ $181 \mathrm{~kg} / \mathrm{m}^{2}$ ), grade 2 obesity (BMI $35.0-39.9 \mathrm{~kg} / \mathrm{m}^{2}$ ) and grade 3 obesity (BMI equal or above $40.0 \mathrm{~kg} / \mathrm{m}^{2}$ ) 182 subgroups.

183 The pain item of the NHP showed abnormally higher scores in women presenting with grade 1,2 184 and 3 obesity compared with overweight women (Table 3), and the physical ability item was also 
185 worse in grade 3 obese women compared with overweight women (Table 3). No other differences 186 among grades of obesity were observed in other NHP items (Table 3).

187 Regarding SF-36, women presenting with grade 2 and 3 obesity had abnormally reduced scores 188 compared with overweight women in the physical functioning item (Table 3), and the general health 189 item was also reduced in women with grade 3 obesity compared with the overweight subgroup (Table $1903)$.

191 Finally, the number of women presenting with scores above the $95^{\text {th }}$ percentile of the NHP scores 192 of the Spanish general population was higher for the physical ability item in obese women compared 193 with overweight women (Table 4), and there was a large percentage of obese presenting with 194 abnormal scores also in the energy and total score of the NHP although not showing differences 195 among grades of obesity (Table 4). Similarly, the number of women presenting with scores below the $1965^{\text {th }}$ percentile of the SF-36 scores of the Spanish general population was higher for the general health 197 item in obese women compared with overweight women (Table 4), and there was a large percentage 198 of obese presenting with abnormal scores also in the physical functioning, role-emotional and social 199 functioning items, although not showing differences among grades of obesity (Table 4).

\section{Discussion}

Our present results suggest that, when adequately paired for weight, there are very few differences 204 among premenopausal women with or without PCOS in their HR-QoL. Our PCOS patients showed 205 worse results compared with the controls only for the role-emotional item of the SF-36 questionnaire. 206 This item evaluates emotional problems that interefere with aspects pertaining to daily life and their 207 laboral sphere. Also, PCOS patients scored lower, and therefore better, in the pain item of the NHP 208 compared with the controls, yet the older age of the later might explain this particular difference 209 because HR-QoL worsens with age. ${ }^{31}$

210 In contrast with the minimal impact of PCOS on HR-QoL, obesity was associated with a broad 211 worsening of many aspects evaluated by the HR-QoL scales used here, in conceptual agreement with 212 previous studies in children and adults. ${ }^{32,33}$ 
213 Compared with overweightness, obesity associated in our series worse scores in the pain and 214 physical ability items of the NHP and in the physical functioning and general health items of the SF215 36. The results regarding the pain and phsysical ability item of NHP may be related to the well-known 216 association of obesity with osteomuscular disorders and with the obvious difficulties that weight 217 excess impose of mobility. ${ }^{34}$ Similarly, obesity exerted a negative impact of the SF-36 items related to 218 daily life activities, including mobility and personal care, influencing the general health perception of 219 these women.

Moreover, when compared with the standards derived from the general population, obese women 221 frequently scored abnormally in the energy, physical ability and total score items of the NHP, and in 222 the general health and physical functioning items of SF-36. Also, the frequencies of abnormal scores 223 tended to be higher with increasing grades of obesity, reaching statistical significance compared with 224 the overweight subgroup for the physical ability item of NHP and the general health item of SF-36. 225 Although quite frequent, the abnormal scores in the role-emotional and social functioning items of SF22636 were similarly distributed in oveweight and obese women. Considering that PCOS was equally 227 prevalent in overweight and obese women in the present series of premenopausal women ${ }^{20}$ this finding 228 possibly reflected the specific impact of PCOS on the emotional aspects of HR-QoL.

229 The negative impact of obesity may explain the worsening of general HR-QoL of PCOS patients 230 in previous studies by others, considering that obesity is frequently associated with PCOS. ${ }^{35}$ The 231 impairment of HR-QoL, psychological well-being and sexual satisfaction in PCOS patients reported in 232 an earlier study conducted in Germany ${ }^{36,37}$ might have been influenced by the fact that this series of 233 German PCOS patients were much heavier compared with their controls and, in sharp contrast with 234 our present study, the German series included many PCOS patients referred for the treatment of 235 infertility, a trait that may impair HR-QoL by itself.

236 In conceptual agreement with our present results, previous studies showed that the differences in 237 HR-QoL among adolescents with or without PCOS dissapeared when controlling for the influece of 238 body mass index, ${ }^{38}$ and no differences in the SF-36 questionnaire were found among PCOS patients 239 and controls in adults when adjusting for weight. ${ }^{16}$ Similarly, body mass index was a significant 240 modifier of the differences in the SF-36 found among Australian PCOS patient and controls, ${ }^{18}$ and a 
Obesity, PCOS and HR-QoL - 10 -

241 recent systematic review highlighted the importance that weight concerns plays in the impairment of 242 HR-QoL in PCOS patients. ${ }^{39}$ The contribution of obesity to the impairment of HR-QoL in PCOS 243 patients was highlighed by the improvement observed after sucessful dietary restriction and life-style 244 modification. $^{40}$

245 However, our present results do not indicate, by any means, that PCOS does not impair HR-QoL 246 by itself. This has been demonstrated in several studies ${ }^{7,16,18}$ by using a disease-specific HR-QoL 247 instrument termed the Polycystic Ovary Syndrome Questionnaire (PCOSQ) that considered 5 domains 248 related to this disorder: emotions, body hair, weight, infertility, and menstrual problems. ${ }^{41,42}$ Our study 249 was, on the contrary, designed to estimate the impact of obesity and PCOS on general HR-QoL 250 instruments, and therefore did not consider disease-specific dimensions that could not be answered by 251 the controls. In fact, many PCOS patients scored abnormally in several items of the NHP and SF-36 252 when compared with the standards derived from the general population.

253 Moreover, the fact that the PCOS patients in our series were younger compared with the controls 254 must be considered when interpreting our present results. As stated above, HR-QoL clearly worsens 255 with age. ${ }^{31}$ Therefore, the age difference in among our PCOS patients and controls might have 256 obscured any difference in general HR-QoL attributable to PCOS. Furthermore, as a whole PCOS 257 patients showed a general HR-QoL similar to non-PCOS women who were several years older, 258 possibility reflecting that their HR-QoL may be inadequately impaired for their younger age.

259 In summary, obesity impaired general HR-QoL to a greater extent than PCOS in overweight and 260 obese premenopausal women. Given the frequent association among both disorders, this finding 261 should be considered when designing therapeutic strategies directed towards the improvement of the 262 quality of life of these women.

263

264 References

265

2661 Guyatt, G.H., Feeny, D.H. \& Patrick, D.L. (1993) Measuring health-related quality of life. Annals 267 of Internal Medicine, 118, 622-629. 
2682 Asuncion, M., Calvo, R.M., San Millan, J.L., Sancho, J., Avila, S. \& Escobar-Morreale, H.F. 269 (2000) A prospective study of the prevalence of the polycystic ovary syndrome in unselected 270 Caucasian women from Spain. Journal of Clinical Endocrinology and Metabolism, 85, 24342712438.

2723 Azziz, R., Carmina, E., Dewailly, D., Diamanti-Kandarakis, E., Escobar-Morreale, H.F., 273 Futterweit, W., Janssen, O.E., Legro, R.S., Norman, R.J., Taylor, A.E. \& Witchel, S.F. (2006) 274 Position statement: criteria for defining polycystic ovary syndrome as a predominantly 275 hyperandrogenic syndrome: an Androgen Excess Society guideline. Journal of Clinical 276 Endocrinology and Metabolism, 91, 4237-4245.

2774 Azziz, R., Carmina, E., Dewailly, D., Diamanti-Kandarakis, E., Escobar-Morreale, H.F., 278 Futterweit, W., Janssen, O.E., Legro, R.S., Norman, R.J., Taylor, A.E. \& Witchel, S.F. (2009) The 279 Androgen Excess and PCOS Society criteria for the polycystic ovary syndrome: the complete task $280 \quad$ force report. Fertility and Sterility, 91, 456-488.

2815 Barth, J., Catalan, J., Cherry, C. \& Day, A. (1993) Psychological morbidity in women referred for 282 treatment of hirsutism. Journal of Psychosomatic Research, 37, 615-619.

2836 Sonino, N., Fava, G., Mani, E., Belluardo, P. \& Boscaro, M. (1993) Quality of life of hirsute 284 women. Postgraduate Medicine, 69, 186-189.

2857 Barnard, L., Ferriday, D., Guenther, N., Strauss, B., Balen, A. \& Dye, L. (2007) Quality of life and 286 psichological well being in polycystic ovary syndrome. Human Reproduction, 22, 2279-2286.

2878 Benson, S., Hahn, S., Tan, S., Mann, K., Janssen, O.E., Schedlowski, M. \& Elsenbruch, S. (2009) 288 Prevalence and implications of anxiety in polycystic ovary syndrome: results of an internet-based 289 survey in Germany. Human Reproduction, 24, 1446-1451.

2909 Deeks, A.A., Gibson-Helm, M.E. \& Teede, H.J. (2010) Anxiety and depression in polycystic 291 ovary syndrome: a comprehensive investigation. Fertility and Sterility, 93, 2421-2423.

29210 Jedel, E., Waern, M., Gustafson, D., Landen, M., Eriksson, E., Holm, G., Nilsson, L., Lind, A.K., 293 Janson, P.O. \& Stener-Victorin, E. (2010) Anxiety and depression symptoms in women with 294 polycystic ovary syndrome compared with controls matched for body mass index. Human $295 \quad$ Reproduction, 25, 450-456. 
Obesity, PCOS and HR-QoL - 12 -

29611 Gambineri, A. \& Pasquali, R. (2006) Insulin resistance, obesity and metabolic syndrome in 297 polycystic ovary syndrome. Endocrinologia y Nutrición, 53(Suppl 1), 49-55.

29812 Sarlio-Lahteenkorva, S., Stunkard, A. \& Rissanen, A. (1995) Psychosocial factors and quality of 299 life in obesity. International Journal of Obesity and Related Metabolic Disorders, 19 Suppl 6, S1$300 \quad 5$.

30113 Lean, M., Han, T. \& Seidell, J. (1999) Impairment of health and quality of life using new US 302 federal guidelines for the identification of obesity. Archives of Internal Medicine, 159, 837-843.

30314 Doll, H., Petersen, S. \& Stewart-Brown, S. (2000) Obesity and physical and emotional well-being: 304 Associations between body mass index, chronic illness, and the physical and mental components 305 of the SF-36 questionnaire. Obesity Research, 8, 160-170.

30615 Kolotkin, R.L., Meter, K. \& Williams, G.R. (2001) Quality of life and obesity. Obesity Reviews, 2, $307 \quad 219-229$.

30816 Coffey, S., Bano, G. \& Mason, H.D. (2006) Health-related quality of life in women with 309 polycystic ovary syndrome: a comparison with the general population using the Polycystic Ovary 310 Syndrome Questionnaire (PCOSQ) and the Short Form-36 (SF-36). Gynecological Endocrinology, $31122,80-86$.

31217 Elsenbruch, S., Benson, S., Hahn, S., Tan, S., Mann, K., Pleger, K., Kimmig, R. \& Janssen, O.E. 313 (2006) Determinants of emotional distress in women with polycystic ovary syndrome. Human $314 \quad$ Reproduction, 21, 1092-1099.

31518 Ching, H.L., Burke, V. \& Stuckey, B.G. (2007) Quality of life and psychological morbidity in 316 women with polycystic ovary syndrome: body mass index, age and the provision of patient 317 information are significant modifiers. Clinical Endocrinology, 66, 373-379.

31819 Jones, G.L., Balen, A.H. \& Ledger, W.L. (2008) Health-related quality of life in PCOS and related 319 infertility: how can we assess this? Human Fertility (Cambridge), 11, 173-185.

32020 Alvarez-Blasco, F., Botella-Carretero, J., San Millan, J. \& Escobar-Morreale, H. (2006) 321 Prevalence and characteristics of the polycystic ovary syndrome in overweight and obese women. 322 Archives of Internal Medicine, 166, 2081-2086. 
21 Zawadzki, J.K. \& Dunaif, A. (1992) Diagnostic criteria for polycystic ovary syndrome: Towards a rational approach. In: Polycystic ovary syndrome, Vol. 4. Blackwell Scientific Publications, Boston, 377-384.

22 The Rotterdam ESHRE/ASRM-sponsored PCOS consensus workshop group. (2004) Revised 327 2003 consensus on diagnostic criteria and long-term health risks related to polycystic ovary syndrome (PCOS). Human Reproduction, 19, 41-47.

23 Escobar-Morreale, H.F., Lasuncion, M.A. \& Sancho, J. (2000) Treatment of hirsutism with ethinyl estradiol-desogestrel contraceptive pills has beneficial effects on the lipid profile and improves insulin sensitivity. Fertility and Sterility, 74, 816-819.

24 Escobar-Morreale, H.F., Sanchon, R. \& San Millan, J.L. (2008) A prospective study of the 333 prevalence of nonclassical congenital adrenal hyperplasia among women presenting with hyperandrogenic symptoms and signs. Journal of Clinical Endocrinology and Metabolism, 93, 527-533.

26 Alonso, J., Prieto, L. \& Anto, J.M. (1994) The Spanish version of the Nottingham Health Profile:

27 Ware, J., Snow, K., Kosinski, M. \& Gandek, B. (1993) SF-36 Health Survey. Manual and 342 interpretation guide. The Health Institute, Boston.

34328 Alonso, J., Regidor, E., Barrio, G., Prieto, L., Rodriguez, C. \& De la Fuente, L. (1998) Population 344 reference values of the Spanish version of the Health Questionnaire SF-36. Medicina Clínica, 111, $345 \quad 410-416$.

34629 Alonso, J., Anto, J. \& Moreno, C. (1990) Spanish version of the Nottingham Health Profile: 347 translation and preliminary validity. American Journal of Public Health, 80, 704-708.

34830 Matsuda, M. \& DeFronzo, R.A. (1999) Insulin sensitivity indices obtained from oral glucose 349 tolerance testing: comparison with the euglycemic insulin clamp. Diabetes Care, 22, 1462-1470. 
35031 Lopez-Garcia, E., Banegas, J., Graciani Perez-Regadera, A., Gutierrez-Fisac, J., Alonso, J. \& 351 Rodriguez-Artalejo, F. (2003) Population-based reference values for the Spanish version of the 352 SF-36 Health Survey in the elderly. Medicina Clínica, 27, 701-709.

35332 Staffieri, J. (1967) A study of social stereotype of body image in children. Journal of Personality $354 \quad$ and Social Psychology, 7, 101-104.

35533 Anandacoomarasamy, A., Caterson, I., Leibman, S., Smith, G., Sambrook, P., Fransen, M. \& 356 March, L. (2009) Influence of BMI on health-related quelity of life: comparison between and 357 obese adult cohort and age-matched population norms. Obesity, 17, 2114-2118.

35834 Bray, G. (2004) Medical consequences of obesity. Journal of Clinical Endocrinology and $359 \quad$ Metabolism, 89, 2583-2589.

36035 Gambineri, A., Pelusi, C., Vicennati, V., Pagotto, U. \& Pasquali, R. (2002) Obesity and the 361 polycystic ovary syndrome. International Journal of Obesity and Related Metabolic Disorders, $362 \quad 26,883-896$.

36336 Elsenbruch, S., Hahn, S., Kowalsky, D., Offner, A.H., Schedlowski, M., Mann, K. \& Janssen, 364 O.E. (2003) Quality of life, psychosocial well-being, and sexual satisfaction in women with 365 polycystic ovary syndrome. Journal of Clinical Endocrinology and Metabolism, 88, 5801-5807.

36637 Hahn, S., Janssen, O.E., Tan, S., Pleger, K., Mann, K., Schedlowski, M., Kimmig, R., Benson, S., 367 Balamitsa, E. \& Elsenbruch, S. (2005) Clinical and psychological correlates of quality-of-life in 368 polycystic ovary syndrome. European Journal of Endocrinology, 153, 853-860.

36938 Trent, M., Austin, S., Rich, M. \& Gordon, C. (2005) Overweight status of adolescent girls with 370 polycystic ovary syndrome: body mass index as mediator of quality of life. Ambulatory Pediatrics, $371 \quad 5,107-111$.

37239 Jones, G.L., Hall, J.M., Balen, A.H. \& Ledger, W.L. (2008) Health-related quality of life 373 measurement in women with polycystic ovary syndrome: a systematic review. Human 374 Reproduction Update, 14, 15-25.

37540 Thomson, R., Buckley, J., Lim, S., Noakes, M., Clifton, P., Norman, R. \& Brinkworth, G. (2009) 376 Lifestyle management improves quality of life and depression in overweight and obese women 377 with polycystic ovary syndrome. Fertility and Sterility, December 11 [Epub ahead of print]. 
37841 Cronin, L., Guyatt, G., Griffith, L., Wong, E., Azziz, R., Futterweit, W., Cook, D. \& Dunaif, A. 379 (1998) Development of a health-related quality-of-life questionnaire (PCOSQ) for women with 380 polycystic ovary syndrome (PCOS). Journal of Clinical Endocrinology and Metabolism, 83, $381 \quad 1976-1987$.

38242 Jones, G.L., Benes, K., Clark, T.L., Denham, R., Holder, M.G., Haynes, T.J., Mulgrew, N.C., 383 Shepherd, K.E., Wilkinson, V.H., Singh, M., Balen, A., Lashen, H. \& Ledger, W.L. (2004) The 384 Polycystic Ovary Syndrome Health-Related Quality of Life Questionnaire (PCOSQ): a validation. 385 Human Reproduction, 19, 371-377. 
Table 1. Clinical and biochemical characteristics in PCOS patients and controls

\begin{tabular}{|c|c|c|c|c|c|c|c|}
\hline \multirow[b]{2}{*}{ Age $(y r)$} & \multicolumn{3}{|c|}{$\begin{array}{l}\text { Patients } \\
(\mathbf{n}=32)\end{array}$} & \multicolumn{3}{|c|}{$\begin{array}{c}\text { Controls } \\
(\mathrm{n}=72)\end{array}$} & \multirow{2}{*}{$\frac{\boldsymbol{P} \text { value }}{<<0.001}$} \\
\hline & 26.1 & \pm & 7.2 & 32.5 & \pm & 7.9 & \\
\hline Body mass index $\left(\mathrm{kg} / \mathrm{m}^{2}\right)$ & 35.7 & \pm & 8 & 35.3 & \pm & 6.2 & 0.41 \\
\hline Waist-hip ratio & 0.82 & \pm & 0.09 & 0.80 & \pm & 0.07 & 0.06 \\
\hline Abdominal circumference $(\mathrm{cm})$ & 95 & \pm & 15 & 94 & \pm & 13 & 0.11 \\
\hline Total body fat (kg) & 35.7 & \pm & 12.2 & 35.8 & \pm & 11.1 & 0.52 \\
\hline Relative body fat (\%) & 38.2 & \pm & 6.9 & 39.5 & \pm & 5.6 & 0.84 \\
\hline Systolic blood pressure $(\mathrm{mmHg})$ & 116 & \pm & 12 & 122 & \pm & 19 & 0.26 \\
\hline Diastolic blood pressure (mmHg) & 69 & \pm & 8 & 72 & \pm & 12 & 0.19 \\
\hline Hirsutism score & 7.3 & \pm & 5.5 & 1.0 & \pm & 1.6 & $<0.001$ \\
\hline Total testosterone (nmol/litre) & 2.2 & \pm & 1.0 & 1.4 & \pm & 0.5 & $<0.001$ \\
\hline Free testosterone (pmol/litre) & 45 & \pm & 21 & 24 & \pm & 10 & $<0.001$ \\
\hline Sex hormone-binding globulin (nmol/litre) & 28 & \pm & 14 & 37 & \pm & 19 & 0.08 \\
\hline 17-hydroxyprogesterone (nmol/litre) & 3.0 & \pm & 1.5 & 1.8 & \pm & 1.2 & 0.007 \\
\hline Androstenedione (nmol/litre) & 12 & \pm & 6 & 8 & \pm & 3 & 0.002 \\
\hline Dehydroepiandrosterone-sulphate ( $\mu \mathrm{mol} /$ litre $)$ & 5.4 & \pm & 2.0 & 4.2 & \pm & 0.2 & 0.25 \\
\hline Luteinizing hormone (U/litre) & 6.1 & \pm & 3.7 & 4.4 & \pm & 2.0 & 0.003 \\
\hline Follicle-stimulating hormone (U/litre) & 5.8 & \pm & 2.9 & 5.9 & \pm & 1.8 & 0.74 \\
\hline Estradiol (pmol/litre) & 169 & \pm & 139 & 195 & \pm & 143 & 0.27 \\
\hline Fasting glucose (mmol/litre) & 5.1 & \pm & 0.6 & 5.3 & \pm & 0.7 & 0.96 \\
\hline Fasting insulin (pmol/litre) & 104 & \pm & 69 & 76 & \pm & 49 & 0.02 \\
\hline Homeostasis model assessment-insulin resistance & 3.5 & \pm & 2.5 & 2.7 & \pm & 1.8 & 0.04 \\
\hline Homeostasis model assessment- $\beta$ & 229 & \pm & 192 & 128 & \pm & 64 & 0.01 \\
\hline Insulin sensitivity index & 3.9 & \pm & 2.6 & 5.2 & \pm & 3.4 & 0.03 \\
\hline Total cholesterol (mmol/litre) & 4.7 & \pm & 1.0 & 4.8 & \pm & 1.0 & 0.39 \\
\hline High-density lipoprotein-cholesterol (mmol/litre) & 1.2 & \pm & 0.2 & 1.2 & \pm & 0.3 & 0.41 \\
\hline Low-density lipoprotein-cholesterol (mmol/litre) & 3.0 & \pm & 0.8 & 3.0 & \pm & 0.8 & 0.49 \\
\hline Triglycerides (mmol/litre) & 1.3 & \pm & 1.0 & 1.1 & \pm & 0.6 & 0.011 \\
\hline Pregnancies (n) & 0.4 & \pm & 0.8 & 1.2 & \pm & 1.4 & 0.001 \\
\hline Deliveries (n) & 0.3 & \pm & 0.5 & 0.9 & \pm & 1.1 & 0.002 \\
\hline Abortions (n) & 0.1 & \pm & 0.4 & 0.3 & \pm & 0.6 & 0.08 \\
\hline
\end{tabular}

Data are means \pm SD. Data were analysed using a general linear model in which age was introduced as a covariate to correct for the difference in age observed between patients and controls. Reproduced from Álvarez-Blasco et al., ${ }^{20}$ with permission. 
Obesity, PCOS and HR-QoL - 17 -

Table 2. Women presenting with abnormal scores in tests of HR-QoL among PCOS patients and controls.

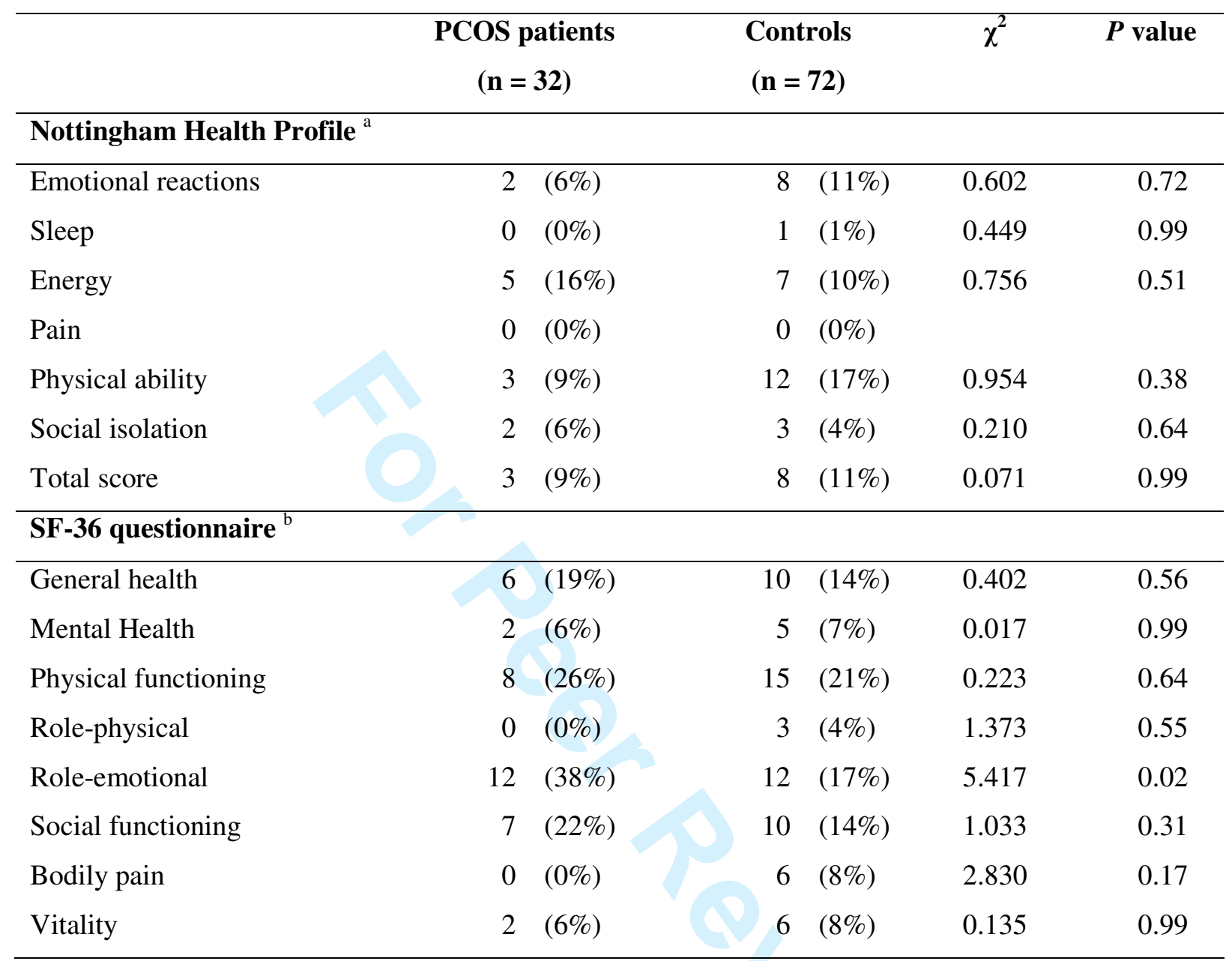

${ }^{\text {a }}$ Data are counts (percentage) of women presenting with scores above the $95^{\text {th }}$ percentile of the Spanish general population.

${ }^{\mathrm{b}}$ Data are counts (percentage) of women presenting with scores below the $5^{\text {th }}$ percentile of the Spanish general population. 
Table 3. Influence of the grade of obesity on HR-QoL scores considering PCOS patients and controls as a whole.

\begin{tabular}{|c|c|c|c|c|c|c|c|c|c|c|c|c|c|c|}
\hline & \multicolumn{3}{|c|}{$\begin{array}{c}\text { Overweight } \\
\left(25.0-29.9 \mathrm{~kg} / \mathrm{m}^{2}\right) \\
n=25\end{array}$} & \multicolumn{3}{|c|}{$\begin{array}{c}\text { Grade } 1 \text { obesity } \\
\left(30.0-34.9 \mathrm{~kg} / \mathrm{m}^{2}\right) \\
\mathrm{n}=35\end{array}$} & \multicolumn{3}{|c|}{$\begin{array}{c}\text { Grade } 2 \text { obesity } \\
\begin{array}{c}\left(35.0-39.9 \mathrm{~kg} / \mathrm{m}^{2}\right) \\
\mathrm{n}=\mathbf{3 0}\end{array}\end{array}$} & \multicolumn{3}{|c|}{$\begin{array}{l}\text { Grade } 3 \text { obesity } \\
\begin{array}{c}\left(>40.0 \mathrm{~kg} / \mathrm{m}^{2}\right) \\
n=23\end{array}\end{array}$} & \multirow[t]{2}{*}{$\chi^{2}$} & $P$ value \\
\hline & & & & & & & & & & & \multicolumn{3}{|c|}{ Nottingham Health Profile } & \\
\hline Emotional reactions & 31 & \pm & 26 & 29 & \pm & 29 & 24 & \pm & 22 & 34 & \pm & 30 & 1.490 & 0.69 \\
\hline Sleep & & \pm & 31 & 24 & \pm & 32 & 23 & \pm & 28 & 20 & \pm & 28 & 0.356 & 0.95 \\
\hline Energy & & \pm & 25 & 27 & \pm & 37 & 22 & \pm & 30 & 39 & \pm & 42 & 5.668 & 0.13 \\
\hline Pain & 4 & \pm & 8 & 16 & \pm & $21^{\mathrm{a}}$ & 19 & \pm & $22^{a}$ & 26 & \pm & $25^{\mathrm{a}}$ & 14.644 & 0.01 \\
\hline Physical ability & 14 & \pm & 14 & 28 & \pm & 23 & 26 & \pm & 25 & 36 & \pm & $27^{\mathrm{a}}$ & 9.940 & 0.02 \\
\hline Social isolation & 10 & \pm & 17 & 8 & \pm & 16 & 5 & \pm & 14 & 11 & \pm & 22 & 2.634 & 0.45 \\
\hline Total score & 16 & \pm & 15 & 22 & \pm & 19 & 20 & \pm & 16 & 28 & \pm & 21 & 4.303 & 0.23 \\
\hline \multicolumn{15}{|l|}{ SF-36 questionnaire } \\
\hline General health & 69 & \pm & 15 & 66 & \pm & 17 & 56 & \pm & 23 & 54 & \pm & $21^{\mathrm{a}}$ & 9.947 & 0.02 \\
\hline Mental Health & & \pm & 16 & 68 & \pm & 17 & 70 & \pm & 19 & 66 & \pm & 23 & 0.717 & 0.87 \\
\hline Physical functioning & 90 & \pm & 15 & 81 & \pm & 20 & 79 & \pm & $19^{a}$ & 71 & \pm & $22^{a}$ & 16.347 & 0.001 \\
\hline Role-physical & 92 & \pm & 21 & 88 & \pm & 26 & 85 & \pm & 27 & 88 & \pm & 24 & 2.090 & 0.55 \\
\hline Role-emotional & 65 & \pm & 41 & 63 & \pm & 46 & 68 & \pm & 40 & 65 & \pm & 43 & 0.111 & 0.99 \\
\hline Social functioning & 80 & \pm & 19 & 79 & \pm & 27 & 80 & \pm & 23 & 72 & \pm & 31 & 0.876 & 0.69 \\
\hline Bodily pain & 68 & \pm & 22 & 64 & \pm & 20 & 65 & \pm & 26 & 55 & \pm & 23 & 0.137 & 0.53 \\
\hline Vitality & 58 & \pm & 16 & 57 & \pm & 19 & 60 & \pm & 21 & 57 & \pm & 23 & 0.558 & 0.91 \\
\hline
\end{tabular}

Data are means \pm SD.

${ }^{a} p<0.05$ compared with overweight women according to Kruskal-Wallis tests, followed by repeated Mann-Whitney tests as post hoc analysis, applying Bonferroni correction to the level of significance. 
Table 4. Women presenting with abnormal scores in tests of HR-QoL depending on their grade of obesity, considering PCOS patients and controls as a whole

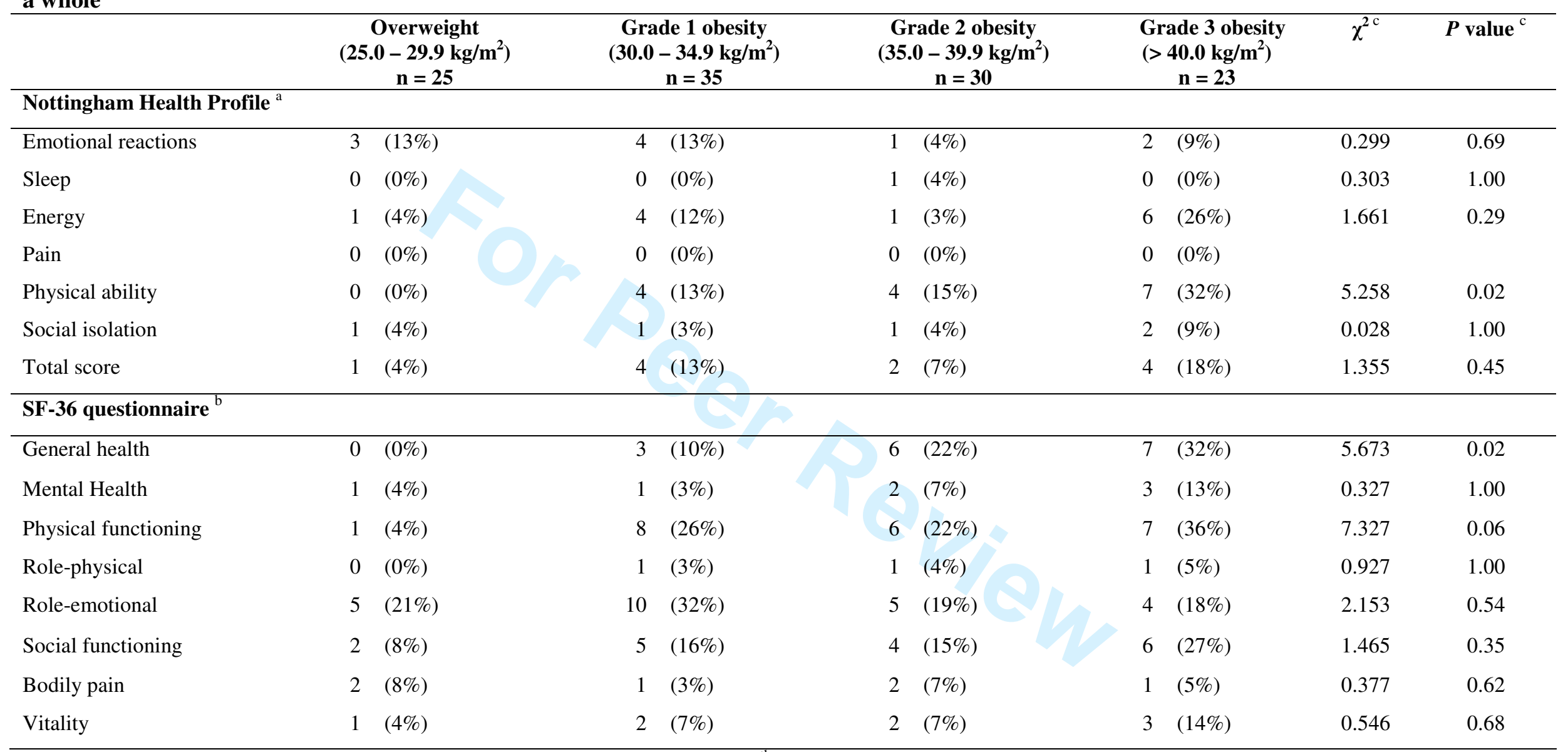

${ }^{\text {a }}$ Data are counts (percentage) of women presenting with scores above the $95^{\text {th }}$ percentile of the Spanish general population.

${ }^{\mathrm{b}}$ Data are counts (percentage) of women presenting with scores below the $5^{\text {th }}$ percentile of the Spanish general population.

${ }^{\mathrm{c}}$ Data were submitted to Fisher's exact test. The grade 1,2 and 3 obesity categories were merged into an obesity category that was compared with the overweight category because, with the exception of physical functioning and role-emotional, for all HR-QoL items there were more than $20 \%$ of cells with expected frequencies below 5 and/or cells with expected categories below 2 , not matching the requirements of the $\chi^{2}$ test. 
Obesity, PCOS and HR-QoL - 20 -

\section{Legend to Figure}

Figure 1. Health-related quality of life scores in PCOS patients and controls. Data are means \pm SEM. ${ }^{\mathrm{a}} p<0.05$ for the comparison of PCOS patients and controls after controlling for a difference in age among them. 

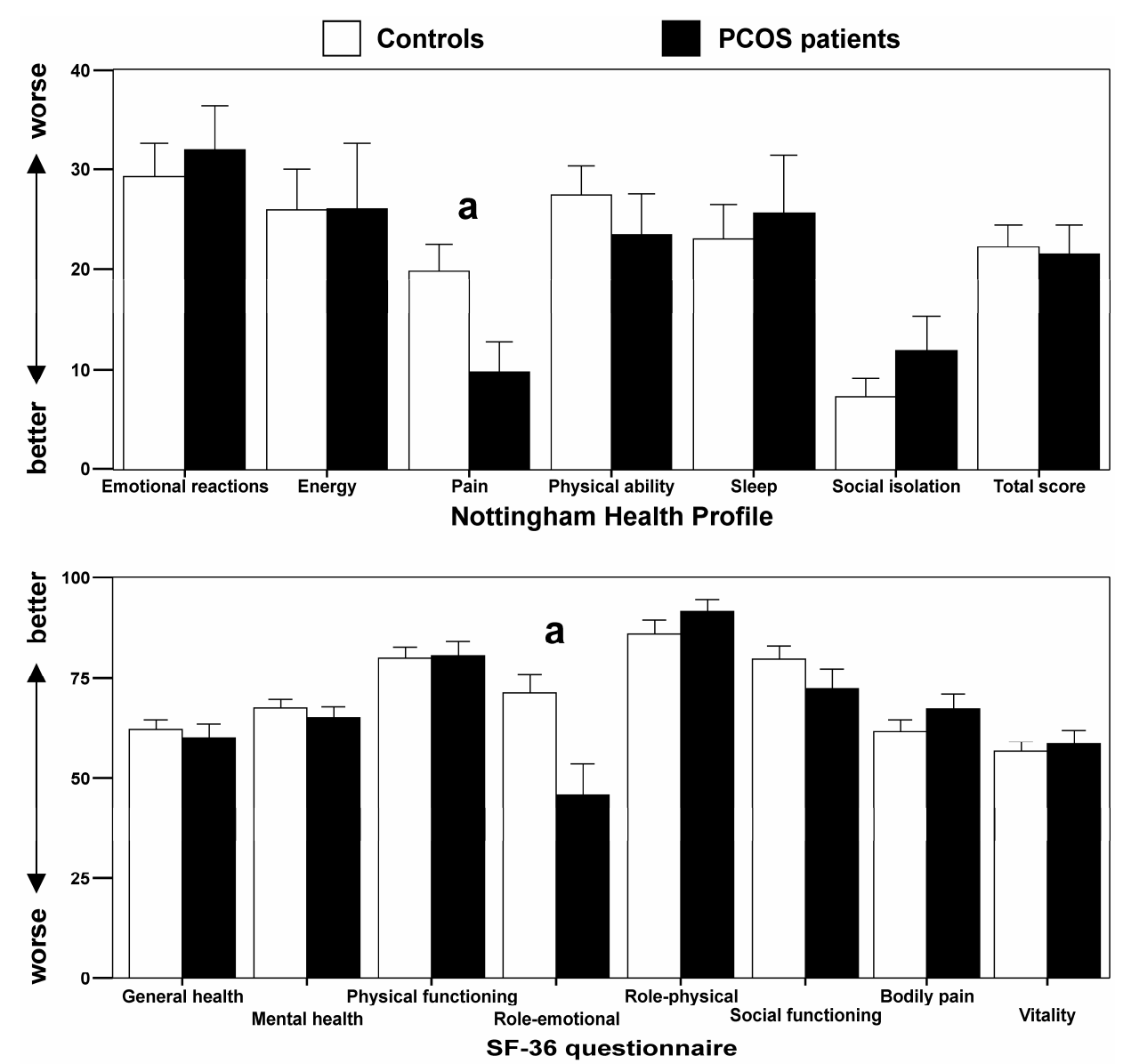

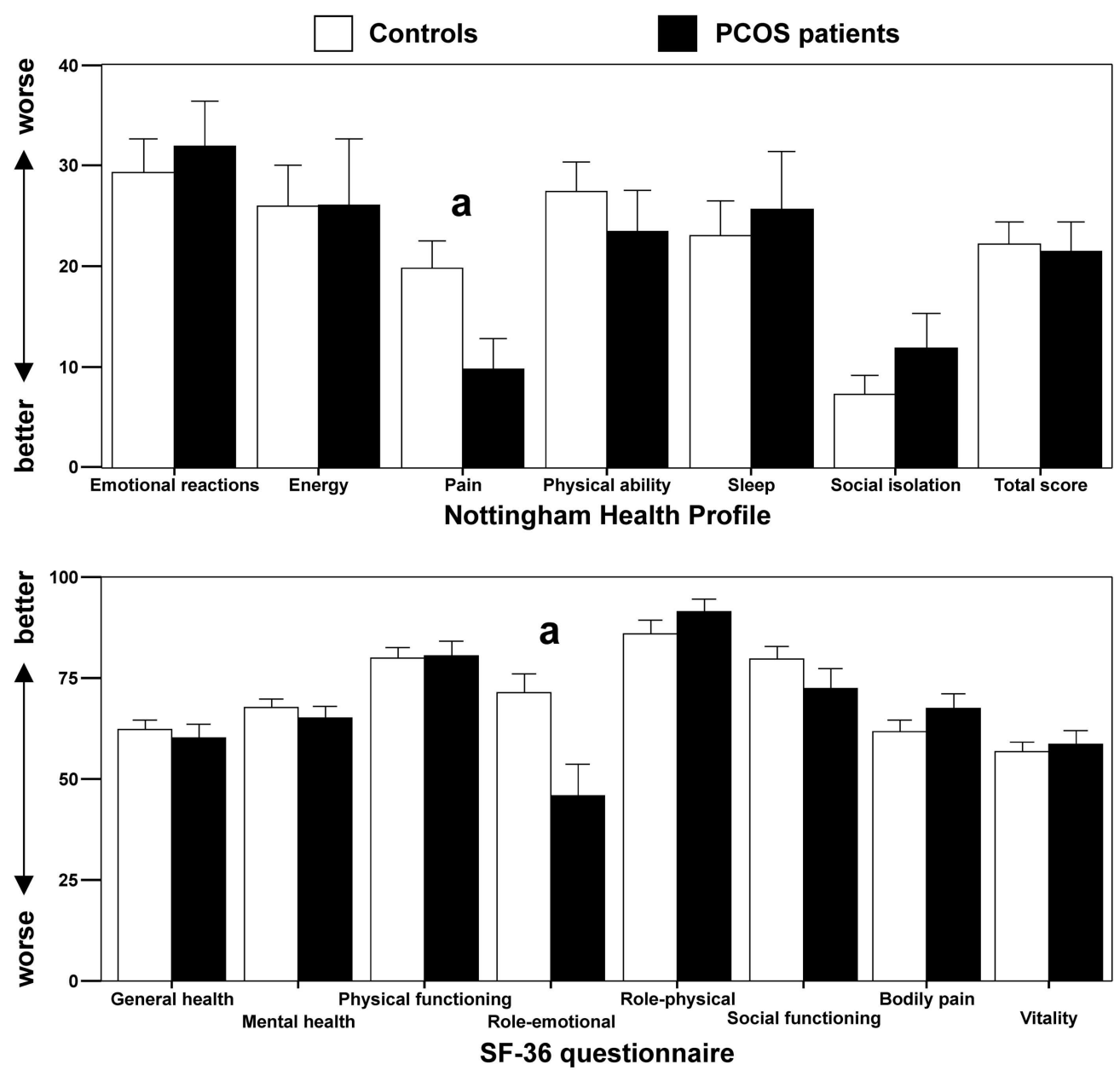

$119 \times 114 \mathrm{~mm}(600 \times 600 \mathrm{DPI})$ 